\title{
A fully integrated microfluidic device for point of care monitoring of antithrombotics
}

L. F. Harris, P. Rainey, Tomas Lindahl and A. J . Killard

The self-archived version of this journal article is available at Linköping University Electronic Press:

http:// urn.kb.se/ resolve?urn=urn:nbn:se:liu:diva- 131721

N.B.: When citing this work, cite the original publication.

Harris, L. F., Rainey, P., Lindahl, T., Killard, A. J., (2016), A fully integrated microfluidic device for point of care monitoring of antithrombotics, Analytical Methods, 8(35), 6500-6505.

https:// dx.doi.org/ 10.1039/ c6ay01566b

Original publication available at:

https:// dx.doi.org/ 10.1039/ c6ay01566b

Copyright: Royal Society of Chemistry

http:// www.rsc.org/ 


\title{
Analytical Methods
}

\section{ARTICLE}

\section{A fully integrated microfluidic device for point-of-care monitoring of antithrombotics}

Received 00th January 20xx,

Accepted 00th January 20xx

DOI: $10.1039 / \times 0 x \times 00000 \times$ www.rsc.org/

\author{
L. F. Harris, ${ }^{a}$ P. Rainey ${ }^{\text {b, T. L. Lindahl' }}$, and A. J. Killard ${ }^{d+}$
}

The simplicity and efficiency of point of care diagnostics have revolutionised patient care. Current methods for measuring hypercoagulability often require trained technicians, large blood volumes, and result in long turnaround times. Standard testing for hypercoagulable disorders is performed in the central laboratory using automated coagulation analysers. However the trend is moving towards the development and implementation of point of care testing, as a result of the ever increasing number of patients on antithrombotic therapy. We present a novel microfluidic device and assay for monitoring the effect of two anticoagulants, unfractionated heparin (UFH) and low molecular weight heparin (LMWH). The assay is based on the anti-Xa assay principle but uses fluorescence detection. Our device is a disposable laminate microfluidic strip, fabricated from the cyclic polyolefin (COP), Zeonor ${ }^{\circledR}$, which is extremely suitable for application to fluorescent device platforms. We present data on the execution of the anti-Xa assay in this microfluidic format, demonstrating that the assay can be used to measure both UFH and LMWH in human plasma samples from 0 to $1 \mathrm{U} / \mathrm{mL}$, with a rapid result obtained within $30-60$ seconds.

\section{Introduction}

Antithrombotics are commonly administered for the treatment of arterial and venous thromboembolism. Unfractionated heparins and low molecular weight heparins are some of the traditional antithrombotics used in the treatment and prevention of such thromboembolic disorders. ${ }^{1}$ Low molecular weight heparin (LMWH) has a more defined and predictable pharmacokinetic or pharmacodynamic profile over unfractionated heparin (UFH) and it also prefers FXa as a therapeutic target over thrombin. ${ }^{2}$

Standard testing for coagulation disorders are usually based on the principle of clotting and are carried out on automated coagulometers. $^{3}$ However with the advent of point of care (POC) diagnostics, many of the standard clotting assays such as the prothrombin time (PT) and activated partial thromboplastin time (aPTT) have been translated into miniaturised POC devices. Warfarin is commonly monitored using the HemoSense INRatio monitor (HemoSense Inc., USA) which was developed for determining the PT/INR of patients undergoing oral anticoagulation treatment. Testing for anticoagulant therapy is very diverse with numerous different tests available for assessing coagulation status, however diagnostics based on the traditional testing principles are

a. College of Sciences and Health, School of Biological Sciences, Dublin institute of Technology, Dublin 8, Ireland.

b. School of Mathematics and Physics, Queen's University Belfast, Belfast, BT7 1NN, Northern Ireland, UK.

c. Department of Clinical and Experimental Medicine, Clinical Chemistry, University of Linköping, Sweden.

d. Department of Applied Sciences, University of the West of England, Frenchay Campus, Coldharbour Lane, Bristol BS16 1QY, UK.

+ Corresponding Author: Prof. Anthony J. Killard, Email: tony.killard@uwe.ac.uk; Tel: + 0044 1173282147; Fax: + 00441173442904. limited in terms of poor predictive value, poor quality and accuracy. ${ }^{4}$ As a result there is a drive for the standardization of current coagulation tests alongside a constant push for the development of a global test of haemostasis. ${ }^{5}$

The emergence of peptide substrates in the $1960 s^{6}$, had a knock-on effect with the development of substrates specific for coagulation proteins. As a result, the chromogenic anti-factor Xa (anti-FXa) assay emerged as the new standard for monitoring LMWH therapy in the central laboratory. The anti-FXa assay works on the principle of the addition of exogenous FXa to a heparinised plasma sample, which is incubated to allow the antithrombin (AT) in the sample to form a complex with the excess FXa and heparin. The formation of this complex allows AT to bind and inihibit thrombin and FXa more strongly. The concentration of free FXa can then be measured using a substrate that is selectively cleaved by the serine protease activity of FXa. $^{7}$ Once cleaved, the peptide substrate will release a chromophore that can be detected colorimetrically.

As the field of microfluidics has advanced, POC technologies have also developed and improved. Methods in microfabrication and microfluidics have progressed so much in the last few years that POC devices can be fabricated at low cost, they are easy to use, portable and can generate rapid results. ${ }^{8,9}$ Silicon, glass, and polymers are often the substrates of choice in the manufacture of microfluidic devices as their chemical and physical properties are well characterized. Silicon and glass can pose issues due to costly fabrication processes, while polymers are low cost. Polymer-based materials are highly versatile in that they suit many modes of fabrication, are suitable for modification with surface chemistries and are also highly reproducible. ${ }^{10}$ In the current study we have used cyclic polyolefins (COPs) which belong to a class of polymers employed due to their compatibility with biological materials, low 
autofluorescence, long shelf life and suitability for surface modification amongst others. ${ }^{11,12}$ Multilayer alignment fabrication methodologies are commonly used to develop functional microdevices ${ }^{13,14}$, as lamination of polymer layers offers greater versatility and low cost. Zeonor ${ }^{\circledR}$ was chosen for this study, in conjunction with PSA (pressure sensitive adhesive), as both are suitable materials for simple fabrication and lamination methodologies. ${ }^{15}$

In our study we have developed a low cost, disposable, miniaturised POC device. We have developed a three layered hybrid chip, comprised of native hydrophobic Zeonor ${ }^{\circledR}$, treated hydrophilic Zeonor $^{\circledR}$ and a PSA spacer that forms the channel. ${ }^{16}$ The assay is incorporated onto the chip and works on the basis of the anti-Xa principle outlined above. Using fluorescence as the method of detection, the assay is capable of measuring therapeutic concentrations of heparin in calibration plasmas from $0-1 \mathrm{U} / \mathrm{mL}$ and in plasma samples from patients on heparin therapy.

\section{Experimental}

\section{Reagents}

Water (ACS reagent) and HEPES (minimum 99.5\% titration) were purchased from Sigma-Aldrich (Dublin, Ireland). Filtered HEPES was prepared at a concentration of $0.01 \mathrm{mM}(\mathrm{pH}$ 7.4). A $100 \mathrm{mM}$ filtered stock solution of $\mathrm{CaCl} 2$ from Fluka BioChemika (Buchs, Switzerland) was prepared from a $1 \mathrm{M} \mathrm{CaCl} 2$ solution.

The fluorogenic substrate methylsulfonyl-D-cyclohexylalanyl-glycylarginine-7-amino-4-methylcoumarin acetate (Pefafluor ${ }^{\mathrm{TM}}$ FXa) was purchased from Pentapharm (Basel, Switzerland). It was reconstituted in $1 \mathrm{ml}$ of water having a stock concentration of 10 $\mathrm{mM}$, aliquoted, covered with aluminum foil to protect from exposure to light, and stored at $-20{ }^{\circ} \mathrm{C}$. Purified human FXa (serine endopeptidase; code number: EC 3.4.21.6) was obtained from HYPHEN BioMed (Neuville-Sur-Oise, France) and was reconstituted in $500 \mu \mathrm{l}$ of PCR grade water to give a stock concentration of 4400 $\mathrm{nM}$. Unfractionated heparin (UFH) (sodium salt of heparin derived from bovine intestinal mucosa, H0777) was sourced from SigmaAldrich (Dublin, Ireland). Low molecular weight heparin tinzaparin (Innohep ${ }^{\circledR}$ ) was obtained from Leo Pharma (Ballerup, Denmark). Human pooled plasma was purchased from Helena Biosciences Europe (Tyne and Wear, UK). Lyophilized plasma was reconstituted in $1 \mathrm{ml}$ of water and left to stabilise for at least $20 \mathrm{~min}$ at room temperature prior to use.

Rolls of $188 \mu \mathrm{m}$ thick cyclic polyolefin polymer (Zeonor ${ }^{\circledR}$ ) were purchased from IBIDI GmbH (Munich, Germany). ARcare ${ }^{\circledR} 9271250$ $\mu \mathrm{m}$ double sided pressure sensitive adhesive (PSA) and HY10coated Zeonor ${ }^{\circledR}$ was purchased from Adhesives Research (Limerick, Ireland). Sheets of $188 \mu \mathrm{m}$ Zeonor ${ }^{\circledast}$ was treated with a hydrophilic coating from Hydromer Inc. (NJ, USA). Conjugate pads (CP) Type $8301 \mathrm{p} / \mathrm{n}$ SMCONO1 were sourced from Pall Europe Ltd. (Portsmouth, England). Strip materials were cut using a Graphtec Vinyl Cutter, Model CE5000-40-CRP from Graphtec GB Limited (Wrexham, UK). Contact angle measurements were carried out using an FTA 200 analyser from First Ten Angstroms, Inc. (Virginia, USA).
All fluorescent measurements were carried out at $37^{\circ} \mathrm{C}$ using an Olympus IX81 motorised fluorescent microscope sourced from Olympus Europa $\mathrm{GmbH}$ (Hamburg, Germany) housed within an incubation chamber with an attached Hamamatsu Orca ER digital camera, Model C4742-80-12AG from Hamamatsu Photonics (Hertfordshire, UK). Fluorescence was monitored according to the following settings: magnification $\times 10$; excitation at $342 \mathrm{~nm}$ and emission at $440 \mathrm{~nm}$; exposure time of $20 \mathrm{~ms}$. All values of fluorescence are reported as arbitrary fluorescence units (AU). All measurements were analyzed using the Cell^ $R$ realtime imaging software from Mason Technology (Dublin, Ireland) with subsequent data exportation into Excel, SigmaPlot 8.0, and SPSS 22.0 for analysis.

\section{Microfluidic Assay and Device Development}

Development of the microfluidic chip was divided into two stages. In the first stage the fluorogenic substrate was deposited within the microfluidic channel, while the FXa reagent was incubated externally with plasma prior to its application on-chip. The results of this study have been published previously. ${ }^{16}$ In the second stage of development, the aim was to develop a fully integrated device with all reagents incorporated on chip.

\section{Integrated Strip Development}

For the development of the integrated strip (Fig. 1), Zeonor ${ }^{\circledR}$ and PSA were cut into multichannel sheets (13 strips) using the Graphtec Vinyl Cutter (Fig. 2) from drawings designed using AutoCAD ${ }^{\circledR}$ 2007. The Zeonor ${ }^{\circledR}$ lid was cut with thirteen elliptical sample inlets of $4 \mathrm{~mm}$ diameter and rectangular outlets of $4 \times 1.5$ $\mathrm{mm}$ to allow air to escape from inside the channels. The PSA channels were $50 \mathrm{~mm}$ long $\times 2 \mathrm{~mm}$ wide, with an additional area cut across the channels at the inlet end, which measured $15 \mathrm{~mm}$ in length by $5 \mathrm{~mm}$ width (Fig. 2). All 3 layers contain alignment marks for easy assembly.

The $\mathrm{CP}$ was also cut to the same dimensions of $15 \mathrm{~cm}$ in length and $5 \mathrm{~mm}$ wide (Fig. 2). Each CP was dip coated in $200 \mu \mathrm{l}$ of FXa and left to dry for 2 hours in a desiccator at $19^{\circ} \mathrm{C}$ and $10 \%$ RH. Dip coating of the conjugate pad took place in a "microdip tank vessel". A scalpel was used to cut the bulb and nozzle from a disposable pipette. The trough created from the bulb is used to contain the FXa. The pipette tip is placed over the needle, to provide a roller which attempts to mimic a standard dip tank coating procedure, while avoiding metal contamination from the needle. Both parts are disposed of after use to avoid cross contamination with future batches.

The PSA layer was bonded to the Zeonor ${ }^{\circledR}$ lid layer using the alignment marks and $2 \mu \mathrm{l}$ of Pefafluor ${ }^{\mathrm{TM}}$ FXa fluorogenic substrate was deposited with a pipette within each channel as four $0.5 \mu \mathrm{l}$ droplets onto the hydrophobic Zeonor ${ }^{\circledR}$ at a distance of $1.5 \mathrm{~mm}$ from the outlet. Sheets were dried for 2 hours in a glass desiccator with silica at $19^{\circ} \mathrm{C}$ and $10 \% \mathrm{RH}$. After drying, the CP was inserted into the cut rectangular area on the PSA and bonded to the hydrophilic Zeonor ${ }^{\circledR}$ base layer using pressure lamination.

Once the strip was assembled, $20 \mu \mathrm{l}$ of re-calcified plasma $(44 \mu \mathrm{l}$ heparinized plasma $+6 \mu \mathrm{l} 100 \mathrm{mM} \mathrm{CaCl}$ ) was immediately applied to the inlet of the assay strip. Plasma samples were spiked with 
pharmacologically relevant concentrations (0-1 U/mL) of UFH and LMWH.

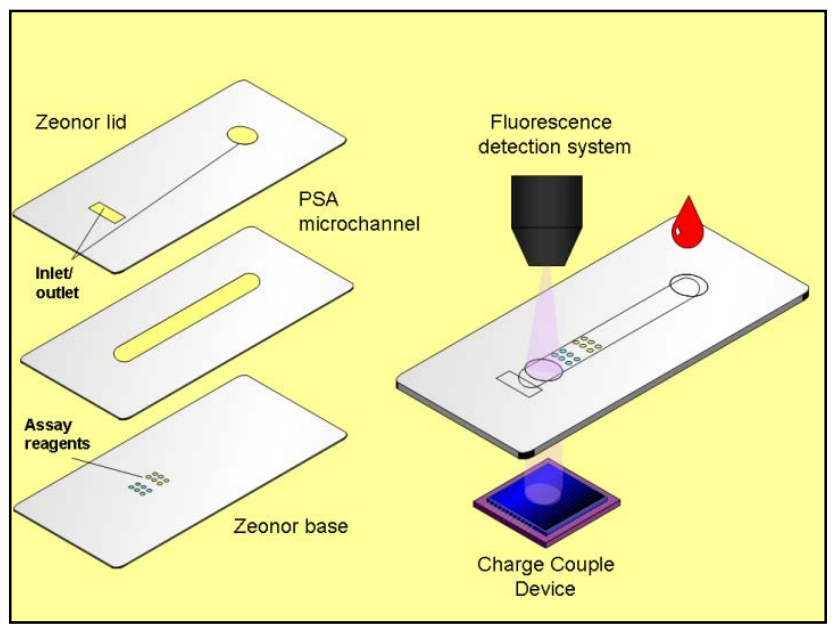

Fig. 1. Schematic of the microfluidic chip highlighting the hydrophobic Zeonor ${ }^{\circledR}$ lid layer (with inlet and outlet), the PSA microchannel layer and the hydrophilic Zeonor base layer with deposited reagents. The image to the right incorporates the microdevice with a miniaturised detection system.

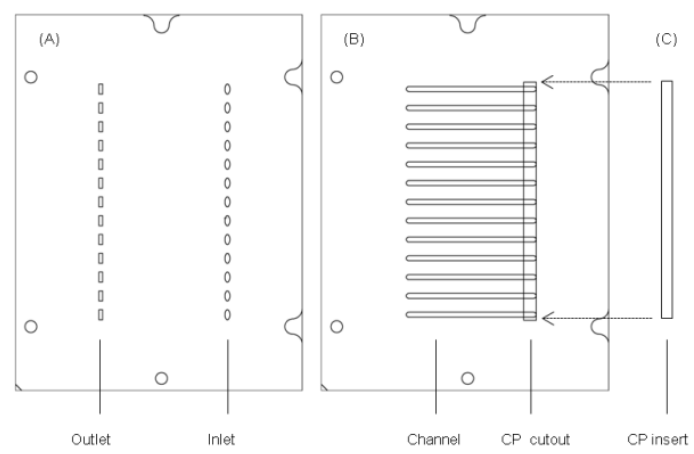

Fig. 2. Multichannel Zeonor ${ }^{\circledR}$ lid layer (A), PSA channel layer (B) and $C P$ containing the FXa reagent $(C)$. The PSA layer containing the CP in the inlet area, was sandwiched between the hydrophilic Zeonor ${ }^{\circledR}$ lid layer and a hydrophobic Zeonor ${ }^{\circledR}$ base layer.

\section{Patient Samples}

A small preliminary study using patient samples was carried out. Plasma samples from patients on UFH were kindly donated by Tomas Lindahl based in the Linköping University Hospital, Sweden. Ten plasma samples from patients on UFH were collected and tested on our microfluidic device platform. Correlations were performed with the assay standard, aPTT for UFH. Patient samples were thawed at $37{ }^{\circ} \mathrm{C}$ in a water bath for $5 \mathrm{~min}$ and inverted for 5 min before testing on the anti-FXa microfluidic device. All measurements were carried out in triplicate.

\section{Results and Discussion}

\section{Strip materials characterisation and selection}

Zeonor ${ }^{\circledast}$ was selected as the polymer of choice for microfluidic chip development due to excellent optical characteristics for fluorescence measurements. A range of surface modifications were tested to render the hydrophobic Zeonor ${ }^{\circledR}$ surface hydrophilic. This allowed for capillary fill of the microfluidic chip. A range of materials were tested in terms of autofluorescence, capillary fill, and contact angle (Table 1).

Table 1: Comparison of commercial hydrophilic surfaces in terms of fluorescence, capillary fill, contact angle and the variability associated with each measurement parameter $(n=3)$.

\begin{tabular}{|c|c|c|c|}
\hline & IBIDI Zeonor ${ }^{\circ}$ & HY10 Zeonor ${ }^{*}$ & Hydromer Zeonor \\
\hline Fluorescence (RFU) & $202.3 \pm 0.1$ & $640.9 \pm 2.3$ & $208.5 \pm 0.1$ \\
\hline Capillary fill (s) & $101 \pm 11.5$ & $23 \pm 1$ & $20.3 \pm 2.1$ \\
\hline Contact angle (s) & $63.4 \pm 2.8$ & $7.6 \pm 0.7$ & $17.5 \pm 0.9$ \\
\hline
\end{tabular}

The HY10 treatment was not selected owing to its significant contribution to background fluorescence (640.9 AU \pm 2.3). Fluorescence readings from the IBIDI Zeonor ${ }^{\circledast}$ and the Hydromer Zeonor $^{\circledR}$ were comparable, but the wettability of the IBIDI treatment was poor by comparison with contact angles of $63.4{ }^{\circ} \pm$ 2.8. As a result the Hydromer treated Zeonor ${ }^{\circledR}$ was selected with a low autofluorescence (208.5 AU) in the UV spectrum, low contact angles $(17.5 \circ \pm 0.9)$ and capillary fill times of $20.3 \mathrm{~s} \pm 2.1$.

A hybrid microfluidic device was developed by combining unmodified Zeonor ${ }^{\circledR}$ with Hydromer-coated Zeonor ${ }^{\circledR}$. This allowed for deposition of reagent onto the hydrophobic film, while the hydrophilic film served to induce capillary fill. The final assay configuration was a three layer laminate chip comprising a $188 \mu \mathrm{m}$ thick hydrophilic base, a $50 \mu \mathrm{m}$ PSA spacer with a channel, into which the conjugate pad was inserted and a $188 \mu \mathrm{m}$ thick hydrophobic Zeonor ${ }^{\circledR}$ lid.

\section{Assay Optimisation and Development}

For the microfluidic chip developed, FXa and Pefafluor FXa' ${ }^{\text {TM }}$ fluorogenic substrate were titrated within the range of 560-760 nM and $100-400 \mu \mathrm{M}$ respectively. Fig. 3 (a) shows the typical fluorescence profiles of a fixed concentration of 600nM FXa to varying concentrations of Pefafluor ${ }^{\mathrm{TM}}$ FXa substrate and Fig. 3 (b) shows the fluorescence responses at $60 \mathrm{~s}$ for 560-700 nM FXa and a fixed concentration of $300 \mu \mathrm{M}$ Pefafluor ${ }^{\mathrm{TM}} \mathrm{FXa}$ in plasma at concentrations of $0,0.5$ and $1 \mathrm{U} / \mathrm{mL} \mathrm{UFH}$. The optimal fluorogenic substrate concentration was selected at a concentration that did not limit the conversion of the substrate to product, which was $660 \mathrm{nM}$ returning an $\mathrm{R}^{2}$ of 0.98 . 

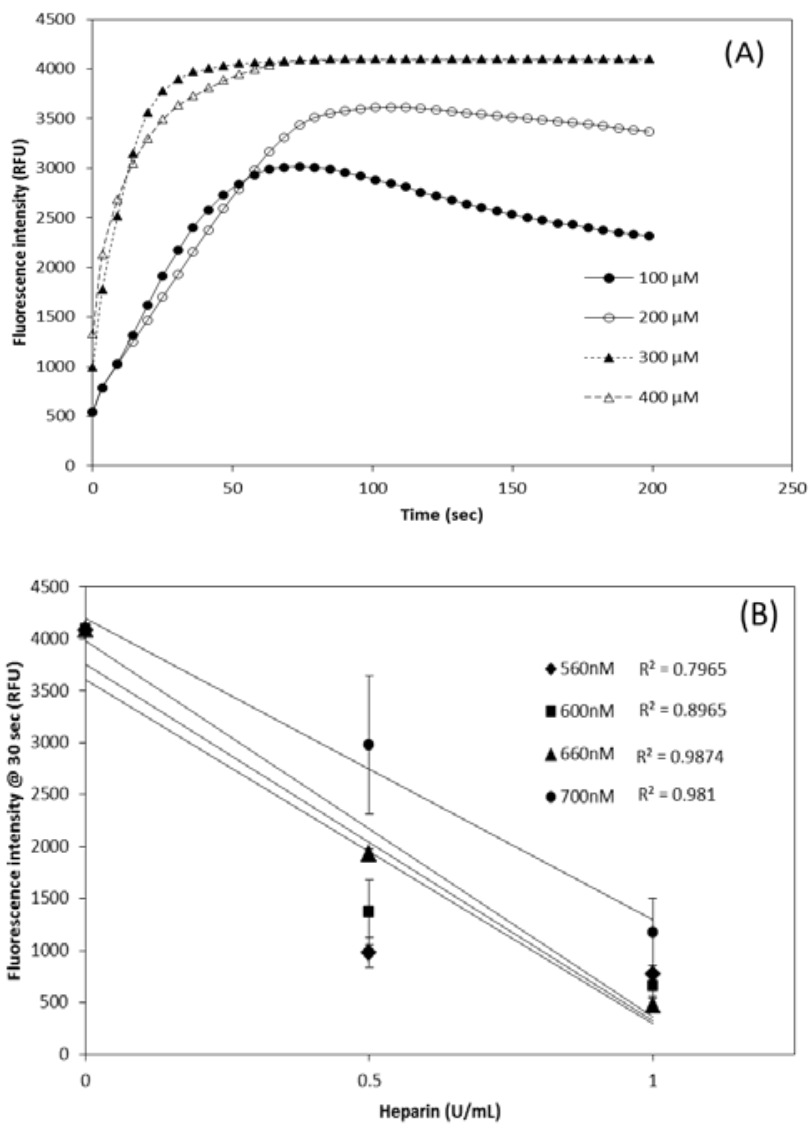

Fig. 3. (a) Typical profiles of the anti-Xa assay at a fixed concentration of $660 \mathrm{nM}$ FXa and varying concentrations of Pefafluor $^{\mathrm{TM}}$ FXa. (b) Fluorescence responses at $30 \mathrm{~s}$ for a range of FXa concentrations and a fixed concentration of $300 \mu \mathrm{M}$ Pefafluor ${ }^{\mathrm{TM}}$ FXa at $0,0.5$, and $1 \mathrm{U} / \mathrm{mL} \mathrm{UFH} \mathrm{(}=3)$.

To select the optimal FXa concentration, the effect of heparin was analyzed using regression analysis (Fig. 4). The optimal concentration of FXa was selected that resulted in a wider signal range than other concentrations, small error and an $\mathrm{R}^{2}$ value close to 0.99 . The optimal concentrations were selected as $300 \mu \mathrm{M}$ Pefafluor $^{\mathrm{TM}}$ FXa substrate and $660 \mathrm{nM}$ FXa for the final assay development of the UFH assay (Fig. 4a). The FXa and Pefafluor ${ }^{\text {TM }}$ FXa fluorogenic substrate concentrations for the LMWH assay were optimized as previously using regression analysis (Fig. 4b). Final concentrations were selected as $650 \mathrm{nM}$ FXa and $600 \mu \mathrm{M}$ Pefafluor $^{\text {TM }}$ FXa fluorogenic substrate.
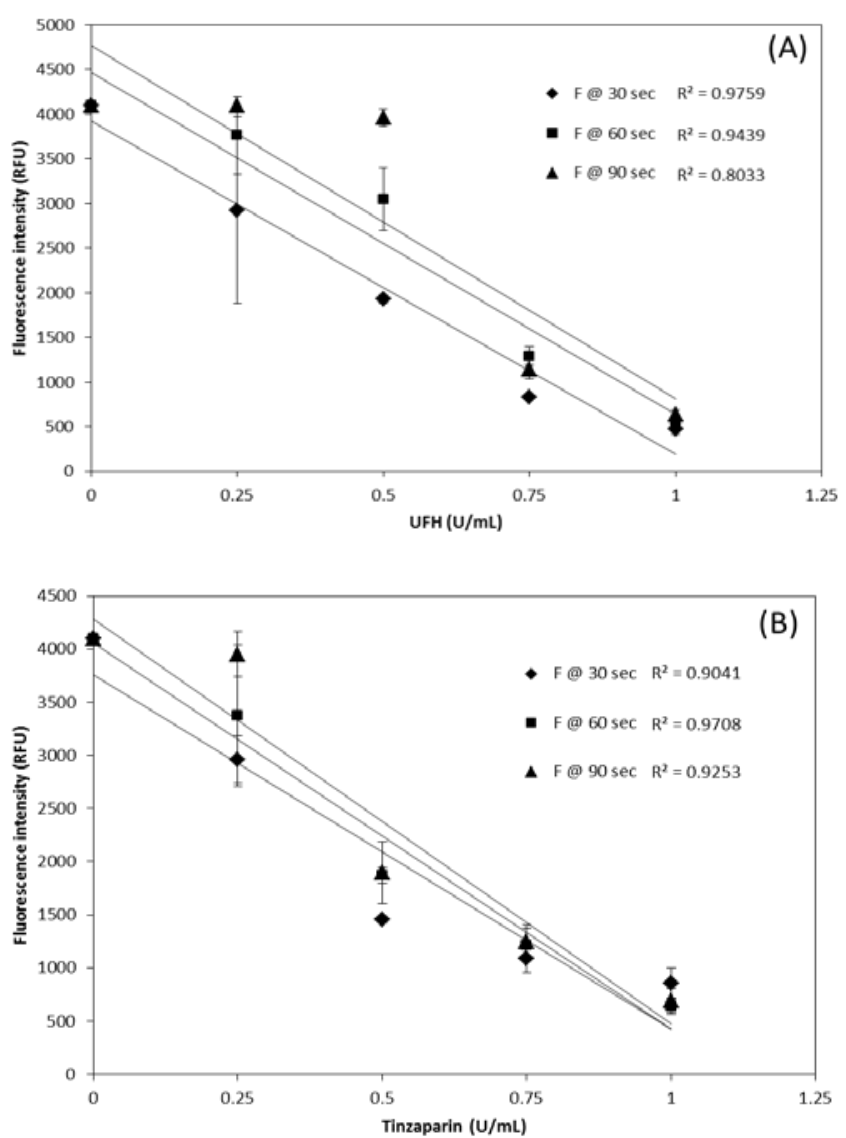

Fig. 4: Linear regression analysis of fluorescent responses at 30, 60 and 90 seconds for (a) UFH and (b) LMWH. The fluorescence value @ 30 seconds was selected as the most appropriate parameter for measuring UFH, while the fluorescence value at 60 seconds was the most appropriate measurement parameter for LMWH.

The fluorescence responses of the optimized assay conditions were tested over a range of UFH and LMWH concentration. The concentration of heparin is inversely proportional to the rate of fluorescence formation. As the concentration of drug increases, the rate of fluorescence product formation decreases. Fig. 5 outlines the dose response curves of human plasma spiked with UFH and $\mathrm{LMWH}$ in the anti-Xa device. Various methods were investigated for optimal data analysis and extraction, but the fluorescence value at $30 \mathrm{sec}$ was most appropriate for UFH returning an $R^{2}$ value of 0.98 $(y=-4309.3 x+4061.1)$ (Pearson $=0.99)$. The fluorescence value at $60 \mathrm{sec}$ was selected as the most appropriate value for LMWH giving an $R^{2}$ value of $0.97(y=-3630 x+4053.8)$ (Pearson $\left.=0.99\right)$. Assay reproducibility was good with average CVs of $<12 \%$ with one exception at $0.25 \mathrm{U} / \mathrm{mL}$ for both the UFH and LMWH assays. Variability at $0.25 \mathrm{U} / \mathrm{mL}$ was $35 \%$ for UFH and $19 \%$ for LMWH assay. Statistical analysis returned significant differences in the variances with the Levene's test for the UFH assay $(p=0.007)$ and the LMWH assay $(p=0.009)$, so one-way ANOVA could not be applied. When equal variances were not assumed, the Tamhane test returned significant differences, however UFH at a concentration of 0.25 $\mathrm{U} / \mathrm{mL}$ resulted in significant error as a result of one outlier causing 
insignificant differences between $0.25 \mathrm{U} / \mathrm{mL}$ and all other concentrations of UFH. The UFH assay had a statistically significant

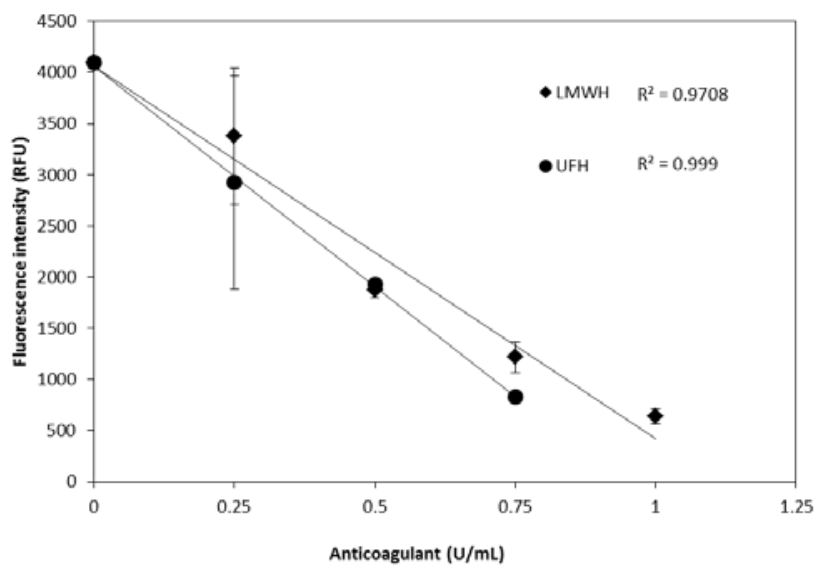

Fig. 5. Dose response curve of human plasma spiked with UFH from $0-1 \mathrm{U} / \mathrm{mL}\left(\mathrm{R}^{2}=0.97\right)$ and $\mathrm{LMWH}$ from $0-1 \mathrm{U} / \mathrm{mL}\left(\mathrm{R}^{2}=0.99\right)$ in the anti-Xa device $(n=3)$.

range from $0-0.75 \mathrm{U} / \mathrm{mL}$. The same pattern was also observed with the LMWH assay where $0.25 \mathrm{U} / \mathrm{mL}$ did not appear significantly different from 0 and $0.5 \mathrm{U} / \mathrm{mL} \mathrm{LMWH}$ and $0.5 \mathrm{U} / \mathrm{mL}$ was not significantly different from $0.75 \mathrm{U} / \mathrm{mL}$. This again could be attributed to the significant outlier encountered at $0.25 \mathrm{U} / \mathrm{mL}$ which resulted in a CV of $19 \%$. Variability of $12 \%$ was also observed at 0.75 $\mathrm{U} / \mathrm{mL}$. The LMWH assay had a statistically significant range from $0-$ $1 \mathrm{U} / \mathrm{mL}$.

\section{Patient Analysis}

To evaluate the integrated device, 10 plasma samples from patients on UFH therapy were tested in the device. For these patients on UFH therapy, the fluorescence responses from all patients were converted into $\mathrm{U} / \mathrm{mL}$ and correlated with the corresponding aPTT value from the hospital laboratory. The correlation can be seen in Fig. 6.

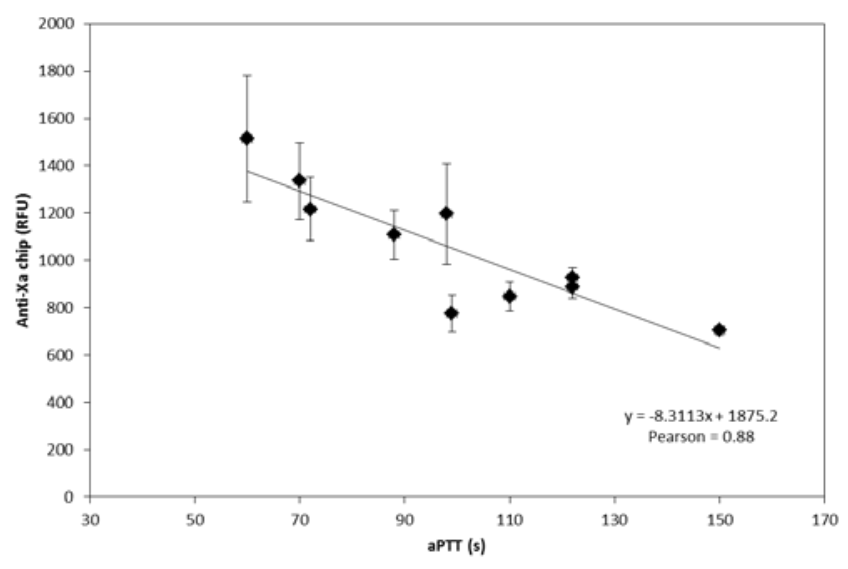

Fig. 6: UFH correlation: Anti-Xa device and hospital aPTT assay. The fluorescence intensity value at 30 seconds was calculated for all UFH patient samples. From the data presented in Fig. 6 it can be seen that UFH generates a good correlation with a Pearson coefficient of 0.88 . The trend observed is that with increasing fluorescence, the aPTT value decreases which is reflective of decreasing heparin concentrations.

Quite a share of the POC market is occupied by coagulation monitoring devices. Many of these POC diagnostics are based on traditional methods and testing principles, such as clotting time determined by PT, aPTT or ACT (activated clotting time). The adaptation of many of these assays to POC devices was instigated by the significant need for more rapid analysis of coagulation status in emergency room settings. ${ }^{16}$ While these devices are commonly used and there is a demand for them, there is certainly scope for the development of novel devices that could improve upon conventional testing methods.

The first move away from standard clot-based testing began in the 1960s with the development and introduction of peptide substrates specific for coagulation proteins such as thrombin and plasmin. ${ }^{17,18}$ Factor Xa was then identified as a significant protein in the coagulation cascade, occupying a pivotal position that could be targeted when monitoring anticoagulant therapy. ${ }^{19}$ The development of a FXa specific peptide substrate resulted in the emergence of the anti-Xa colorimetric assay in 1976 which was used to monitor heparin therapy. ${ }^{6}$ Central diagnostic laboratories refer to the the anti-Xa assay as the 'gold standard' assay for measuring heparin anticoagulant therapy. Despite its popularity, it has not yet been translated into a POC device.

The work presented here focuses on the development of a POC device for monitoring anticoagulant therapy in cardiac patients that operates on the anti-Xa assay principle. Our initial aim was to develop a simple disposable chip that incorporates the anti-Xa assay. The simplicity of the chip is achieved through the mechanism of capillary fill, so there is no integration of complex, sophisticated, and costly instrumentation such as pumps or valves into the device. The chip was fabricated from $188 \mu \mathrm{m}$ Zeonor ${ }^{\circledR}$ which is easily manipulated during manufacture on the Graphtec Vinyl Cutter. Other microfluidic techniques such as laser ablation or hot embossing can be costly to operate and often require skilled operators, compared to cutting plotters which are user friendly and low cost alternatives.

As aforementioned, COP was chosen as the substrate material for this chip design as it offers additional advantages over polymers such as polycarbonate (PC) and polyethylene terephthalate (PET) in terms of its excellent optical clarity, high UV transmission, easy modification of its surface and suitability for disposable POC devices. ${ }^{20-22}$

The concept of capillary force has long been used in lateral flow tests which are the most commercially successful POC platforms due to their simplicity. ${ }^{23}$ Native Zeonor ${ }^{\circledR}$ is highly hydrophobic which is suitable for reagent deposition but it becomes problematic when working with devices using capillary fill as it prevents flow. To render the Zeonor $^{\circledR}$ surface hydrophilic, three surface chemistries were analyzed to modify the polymer. From the results obtained, the Hydromer-modified Zeonor ${ }^{\circledR}$ with low water contact angles of $17.5^{\circ} \pm 0.9$, produced the most reproducible capillary fill times of 
$20.3 \mathrm{~s} \pm$ 2.1. The device was based on a joint hydrophilic/hydrophobic design to incorporate both the reagent deposition and capillary fill components of the device. The method of detection for this device is based on fluorescence, so Zeonor ${ }^{\circledR}$ was selected, as it resulted in low background fluorescence at wavelengths of $342 \mathrm{~nm}$. Treatment with the HY10 coating resulted in responses of $640.9 \pm 2.3 \mathrm{AU}$, which were too high in terms of background fluorescence.

The fully integrated device developed showed sensitivity in the therapeutic ranges for UFH $(0-0.75 \mathrm{U} / \mathrm{mL})$ and LMWH $(0-1$ $\mathrm{U} / \mathrm{mL}$ ). Average $\mathrm{CVs}$ were $<11 \%$, despite high $\mathrm{CVs}$ at $0.25 \mathrm{U} / \mathrm{mL}$ which would be reduced with further device development.

Comparisons on levels of sensitivity and precision can only be drawn with clot-based devices for heparin measurement currently on the market, as an optical POC system for anticoagulant monitoring is not currently available. Comparisons can be drawn with the Hemochron ${ }^{\circledast}$ systems which are some of the most commonly used POC coagulation devices on the market Hemochron ${ }^{\circledR}$ aPTT measurements report linearity with heparin up to $1.5 \mathrm{U} / \mathrm{mL}$, at intervals of $0.25 \mathrm{U} / \mathrm{mL}$ and $\mathrm{CVs}$ of $<14 \%$. Our system is also outperforming other POC diagnostics in terms of volume and turnaround times. The anti-Xa assay and device requires a small sample volume of $20 \mu \mathrm{l}$ and results processed within 30 or 60 seconds. This correlates with devices such as the CoaguCheck (Roche Diagnostics, UK), yet significantly lower than the $50 \mu \mathrm{l}$ sample volume required for the Hemochron ${ }^{\circledR}$ systems.

\section{Conclusion}

In terms of patient analysis, plasma samples from patients on UFH were tested on the device and a Pearson correlation of 0.88 was achieved by comparing fluorescence with clotting time. With low heparin concentrations, fluorescence intensities are high and clotting times are short. Here we present preliminary results of a POC anti-Xa device but with further development, the fluorogenic anti-Xa assay and device could prove successful for near-patient monitoring of antithrombotics with the knock-on effect of improving the health of patients on anticoagulant drugs.

\section{Acknowledgements}

This work was supported by Enterprise Ireland under Grant No. TD/2009/0124.

\section{References}

1 B. Wood and L. Fitzpatrick, Formulary, 2010, 45, 91-100.

2 J. Fareed, I. Thethi and D. Hoppensteadt, Annu. Rev. Pharmacol. Toxicol., 2012, 52, 79-99.

3 J. Hirsh, T. E. Warkentin, S. G. Shaughnessy, S. S. Anand, J. L. Halperin, R. Raschke, C. Granger, E. M. Ohman and J. E. Dalen, Chest, 2001, 119, 64S-94S.

4 T. Baglin, T. W. Barrowcliffe, A. Cohen and M. Greaves, Br. J. Haematol., 2006, 133, 19-34.

5 L. K. Jennings and J. Kotha, Drug Dev. Res., 2013, 74, 587-593.

6 A. N. Teien, M. Lie and U. Abildgaard, Thromb. Res., 1976, 8, 413-416.

7 S. Middeldorp, Thromb. Res., 2008, 122, 753-762.

8 G. M. Whitesides, Nature, 2006, 442, 368-373.
9 V. Linder, Analyst, 2007, 132, 1186-1192.

10 T. G. Henares, F. Mizutani and H. Hisamoto, Anal. Chim. Acta, 2008, 611, 17-30.

11 C. Jonsson, M. Aronsson, G. Rundstroem, C. Pettersson, I. Mendel-Hartvig, J. Bakker, E. Martinsson, B. Liedberg, B. MacCraith, O. Oehman and J. Melin, Lab Chip, 2008, 8, 1191-1197.

12 M. M. Dudek, R. P. Gandhiraman, C. Volcke, S. Daniels and A. J. Killard, Plasma Process Polym., 2009, 6, 620-630.

13 B. L. Thompson, Y. Ouyang, G. R. M. Duarte, E. Carrilho, S. T. Krauss and J. P. Landers, Nat. Protoc., 2015, 10, 875-886.

14 W. K. Tomazelli Coltro, C.-M. Cheng, E. Carrilho and D. P. de Jesus, Electrophoresis, 2014, 35, 2309-2324.

15 H. Sharma, D. Nguyen, A. Chen, V. Lew and M. Khine, Ann. Biomed. Eng., 2011, 39, 1313-27.

16 L. F. Harris, P. Rainey, V. Castro-López, J. S. O’Donnell and A. J. Killard, Analyst, 2013, 138, 4769-76.

17 J. Fareed, H. L. Messmore and E. W. Bermes, Clin. Chem., 1980, 26, 1380-1391.

18 H. L. J. Messmore, J. Fareed, J. Kniffin, G. Squillaci and J. Walenga, Ann. N. Y. Acad. Sci., 1981, 785-797.

19 J. Ansell, J. Thromb. Haemost., 2007, 5, 60-64.

20 L. Brown, T. Koerner, J. H. Horton and R. D. Oleschuk, Lab Chip, 2006, 6, 66-73.

21 V. Gubala, L. F. Harris, A. J. Ricco, M. X. Tan and D. E. Williams, Anal. Chem., 2012, 84, 487-515.

22 A. Bhattacharyya and C. M. Klapperich, Anal. Chem., 2006, 78, 788-792.

23 D. Mark, S. Haeberle, G. Roth, F. von Stetten and R. Zengerle, Chem. Soc. Rev., 2010, 39, 1153-1182. 